\title{
Microcontroller Based Electrical Parameter Monitoring System of Electronic Load Controller Used in Micro Hydro Power Plant
}

\author{
Nan Win Aung, Aung Ze Ya \\ Department of Electrical Power Engineering, Mandalay Technological University, Mandalay, Myanmar
}

Email address:

nanwinaung.ep@gmail.com (N. W. Aung),dr.aungzeya010@gmail.com (A. Z. Ya)

To cite this article:

Nan Win Aung, Aung Ze Ya. Microcontroller Based Electrical Parameter Monitoring System of Electronic Load Controller Used in Micro Hydro Power Plant. Journal of Electrical and Electronic Engineering. Vol. 3, No. 5, 2015, pp. 97-109. doi: 10.11648/j.jeee.20150305.11

\begin{abstract}
In stand-alone micro-hydro power system, water turbine will vary in speed due to the variation of consumer load. This speed variation will cause in fluctuation in both voltage and frequency output from a generator. To solve this problem, electronic load controllers were invented and used in micro-hydro power system. The objective of this paper is to monitor the electrical parameters such as voltage, current, power and frequency of electronic load controller (ELC) by using microcontroller and liquid crystal display (LCD). It explains how to monitor and sense the above parameters and isolate between the power line and microcontroller. The voltage is sensed by using the step down transformer and voltage divider circuit. The current is measured with the help of an ACS 712 current sensor. Frequency signal is obtained by using a frequency signal converter circuit. Microcontroller 16F887 and liquid crystal display are used as the main devices to monitor the above parameters according to the values obtaining from the sensing circuits.
\end{abstract}

Keywords: Electronic Load Controller (ELC), Electrical Parameters Such as Voltage, Current, Power and Frequency, Liquid Crystal Display (LCD), Monitoring System, Microcontroller, Micro Hydro Power Plant

\section{Introduction}

The problem in micro-hydro power system is fluctuation in frequency and voltage generated by the generator under consumer load variation. The fluctuation in frequency and voltage cause adverse affect in various electrical appliances. Electronic Load Controller (ELC) is used to solve that problem. Control is done by diverting the unused power to the ballast load. An ELC is a solid state electronic device designed to regulate output power of a micro-hydro power system and maintaining a near-constant load on the turbine. Monitoring system is required to inform and check the present parameter values to an operator when micro hydro power system is running on load.

Electrical parameters in the system are voltage, current, frequency, power and power factor. There are three types of power in the system such as apparent power (S) in VA, active power $(\mathrm{P})$ in $\mathrm{W}$ and reactive power $(\mathrm{Q})$ in var. Apparent power can be measured by using the voltage and current values. However, power factor measurement is needed to measure the active and reactive power when the load is not the pure resistive loads. But the main parameters of ELC are the system voltage and frequency. Because the purpose of ELC control is to be stable the system voltage and frequency. Therefore, only apparent power $(\mathrm{S})$ is measured and simulated in this paper. Microcontroller based electronic load controller (ELC) should be added with microcontroller based monitoring system to be a perfect and more advance the controller.

\section{Principle Operation of ELC}

The synchronous generator-ELC system consists of a three-phase star-connected generator driven by a micro hydro turbine and an ELC. Since the input power is nearly constant, the output power of synchronous generator is held constant at varying consumer loads. The power in surplus of the consumer load is dumped in a dump load through the ELC. Thus, synchronous generator feeds two loads in parallel such that the total power is constant, that is,

$$
\mathrm{PG}=\mathrm{PC}+\mathrm{PD}
$$

Where,

$\mathrm{PG}=$ Generated power of the generator (which should be kept constant), 
$\mathrm{PC}=$ Consumer load power, and

$\mathrm{PD}=$ Dump load power

The power dissipated in the dump load can be used for battery charging, water heating, cooking, etc[13].

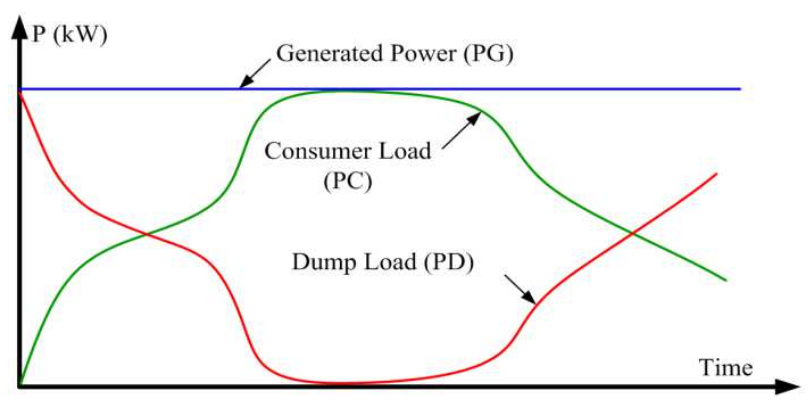

Figure 1. Principle operation of ELC.

The main type of ELC designs that are prevalent are:

- Binary load regulation

- Phase angle regulation

- Pulse width regulation

- Controlled bridge rectifier

- Uncontrolled bridge rectifier with a chopper

\subsection{Binary Load Regulation}

In binary load regulation the ballast load is made up from a switched combination of binary arrangement of separate resistive loads. In response to a change in the consumer load, a switching selection is made to connect the appropriate combination of load steps. This switching operation occurs during the transient period only, thereafter full system voltage is applied to the new fraction of the ballast load and hence harmonics are not produced by this method in the steady-state. In addition, it is usually the practice to adopt solid-state switching relays which include a zero-voltage switching circuit that reduces the harmonic distortion associated with the transient switching period [3]. The number of dump loads and the associated wiring is high and to achieve smooth regulation, these dump loads should all have exactly the right capacity. With a low number of dump loads, steps between dump load combinations remain too large and the system cannot regulate smoothly[4].

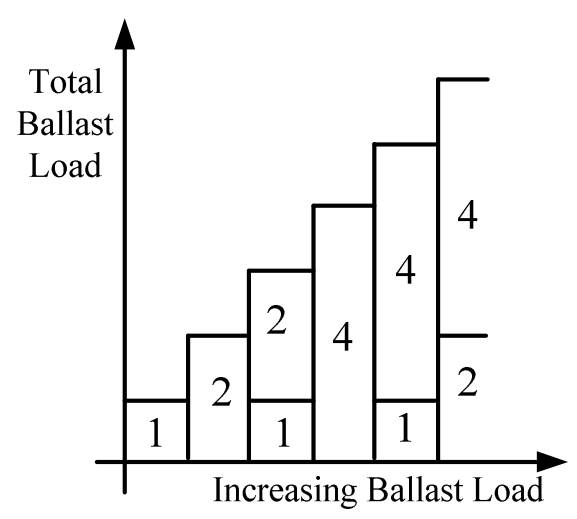

Figure 2. Binary weighted ballast load.

\subsection{Phase Angle Regulation}

In phase angle regulation, the ballast load comprises of a permanently connected single resistive load circuit of magnitude equal to (or slightly greater than) the full load rated output of the generator. As a result of the detection of a change in the consumer load, the firing angle of present power electronic switching device, such as a triac, is adjusted, thus altering the average voltage applied to and hence the power dissipated by, the ballast load.

As with all power electronic switching of this nature, this technique introduces harmonics onto the electrical system. In phase angle regulation method some of the shortcomings present are the presence of harmonics and that effectiveness limited by timing accuracy of trigger pulse. Phase angle modulation also seriously distorts the generator and this leads to the increasing of size of the generator to almost $25 \%$.
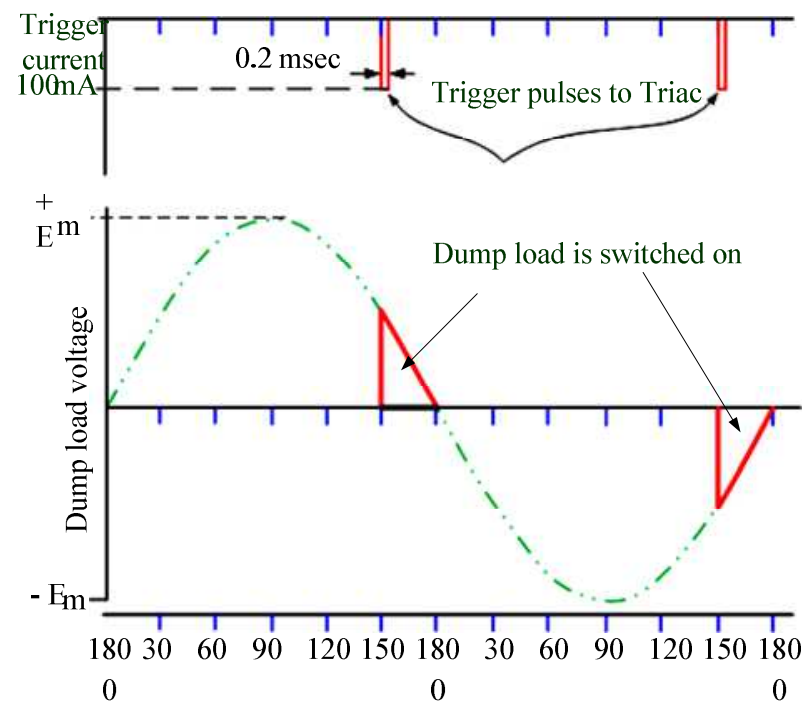

Figure 3. Firing angle of phase angle regulation.

\subsection{Pulse Width Regulation}
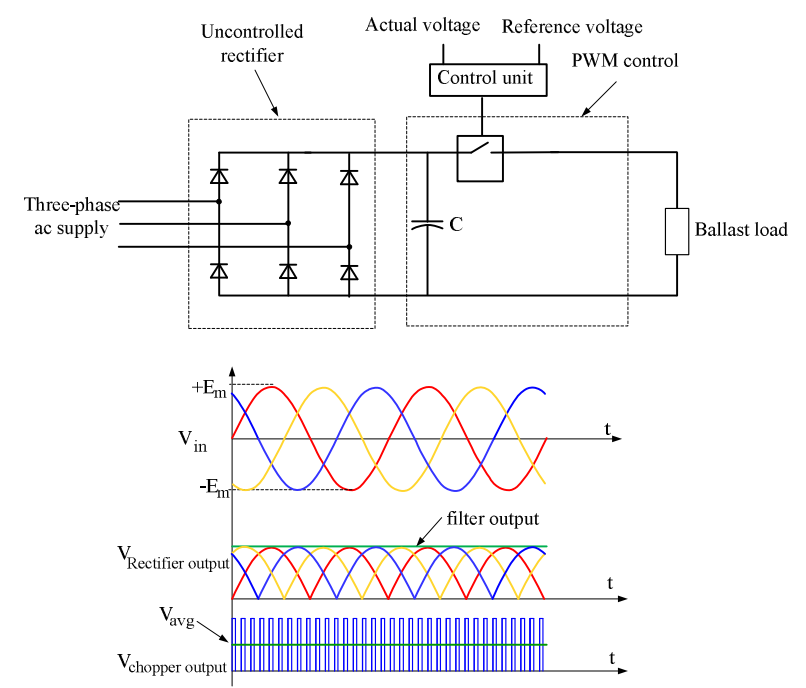

Figure 4. Circuit diagram of uncontrolled rectifier with pulse width regulation control. 
In pulse width regulation, $\mathrm{AC}$ voltage is first rectified and dump load is switched on and off with a variable duty cycle. Duty cycle is the ratio of switch on time of a cycle to the time for a cycle. Control is done by varying the on-time of a cycle when the time of a cycle is constant for fixed frequency. PWM control can have fast response and compared to other schemes they usually have very smooth speed control, but total heat that is produced in this type of ELC is high and this is due to current problems with both rectifier and the transistor switching losses is really noticeable and significant in high frequency [3].

\subsection{Controlled Bridge Rectifier}

In controlled bridge rectifier, $\mathrm{AC}$ voltage is not only rectified to DC voltage but also controlled to variable DC output voltage whose magnitude is varied by phase control. So, a controlled bridge rectifier involves both conversion and control of electrical power. To achieve both conversion and control of electrical power, silicon controlled rectifiers (SCR) which are also called thyristors are used in power circuit as the power electronic devices. To turn SCR on, gate pulse must be provided to the gate of SCR. To achieve the dump load control, the rectifier output voltage is controlled by varying the delay time of gate pulse called delay angle $(\alpha)$.

As phase angle regulation, this technique introduces harmonics onto the electrical system. Moreover the timing accuracy of trigger pulses is very complex and limits the effectiveness of the system.

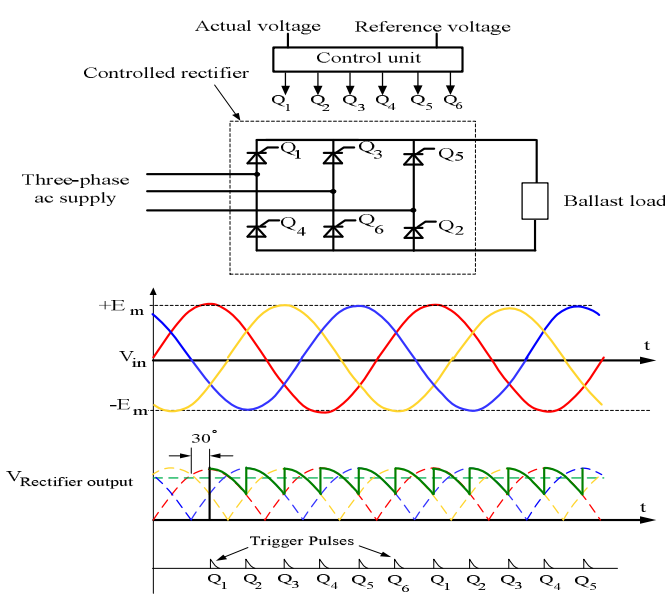

Figure 5. Circuit diagram of controlled rectifier regulation.

\subsection{Uncontrolled Bridge Rectifier with a Chopper}

In uncontrolled bridge rectifier with a chopper, $\mathrm{AC}$ voltage is first rectified to DC voltage and then a chopper controls it to variable DC voltage by varying the chopper duty cycle (D) for dump load control. Dump load power is controlled by adjusting the duty cycle (D). It is very similar to pulse width regulation method except the chopper design. But it has two control methods such as pulse width modulation and pulse frequency modulation. In pulse frequency modulation, the time of a cycle must be varied for frequency modulation when the switch on time is constant [4].
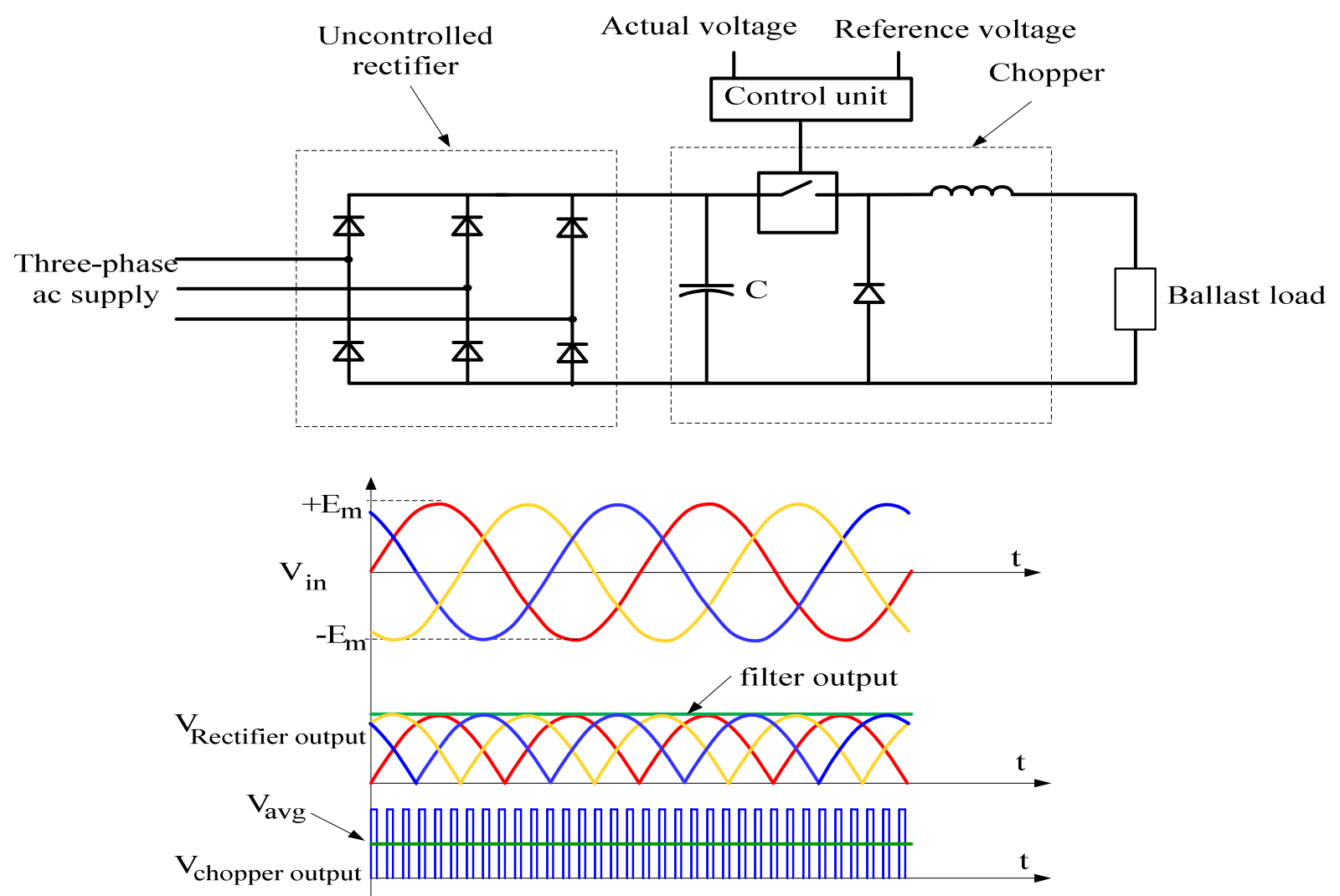

Figure 6. Circuit diagram of uncontrolled rectifier with a chopper. 
Table I. Advantages and disadvantages of control methods.

\begin{tabular}{|c|c|c|}
\hline Method & Advantages & disadvantages \\
\hline Binary load regulation & -Minimal harmonics & $\begin{array}{l}\text {-Fixed damp load size } \\
\text {-Requires large number of dump load } \\
\text {-Effectiveness limited by number of dump loads. } \\
\text {-Harmonics }\end{array}$ \\
\hline Phase angle regulation & -Can use any number/size combination of dump load & $\begin{array}{l}\text {-Effectiveness is limited by timing accuracy of trigger pulse. } \\
\text {-Control system is complex. }\end{array}$ \\
\hline Pulse width regulation & $\begin{array}{l}\text {-Can use any number/size combination of dump load } \\
\text {-Control system is simplest. }\end{array}$ & $\begin{array}{l}\text {-Harmonics } \\
\text {-Effectiveness is limited by timing accuracy of duty cycle. } \\
\text {-Harmonics }\end{array}$ \\
\hline Controlled bridge rectifier & -Can use any number/size combination of dump load & $\begin{array}{l}\text {-Effectiveness is limited by timing accuracy of trigger pulse. } \\
\text {-Control system is complex. }\end{array}$ \\
\hline $\begin{array}{l}\text { Uncontrolled bridge rectifier with } \\
\text { a chopper }\end{array}$ & -Can use any number/size combination of dump load & $\begin{array}{l}\text {-Harmonics } \\
\text {-Effectiveness is limited by timing accuracy of duty cycle. }\end{array}$ \\
\hline
\end{tabular}

\section{Proposed ELC Design and System Configuration}

The selected method for proposed $15 \mathrm{~kW} \mathrm{ELC} \mathrm{is} \mathrm{the}$ combination of binary load regulation and pulse width regulation. Because binary load regulation is minimal harmonics and pulse width regulation is fast respond compared to others schemes.

Proposed ELC design can be divided into two circuits such as control circuit and power circuit.

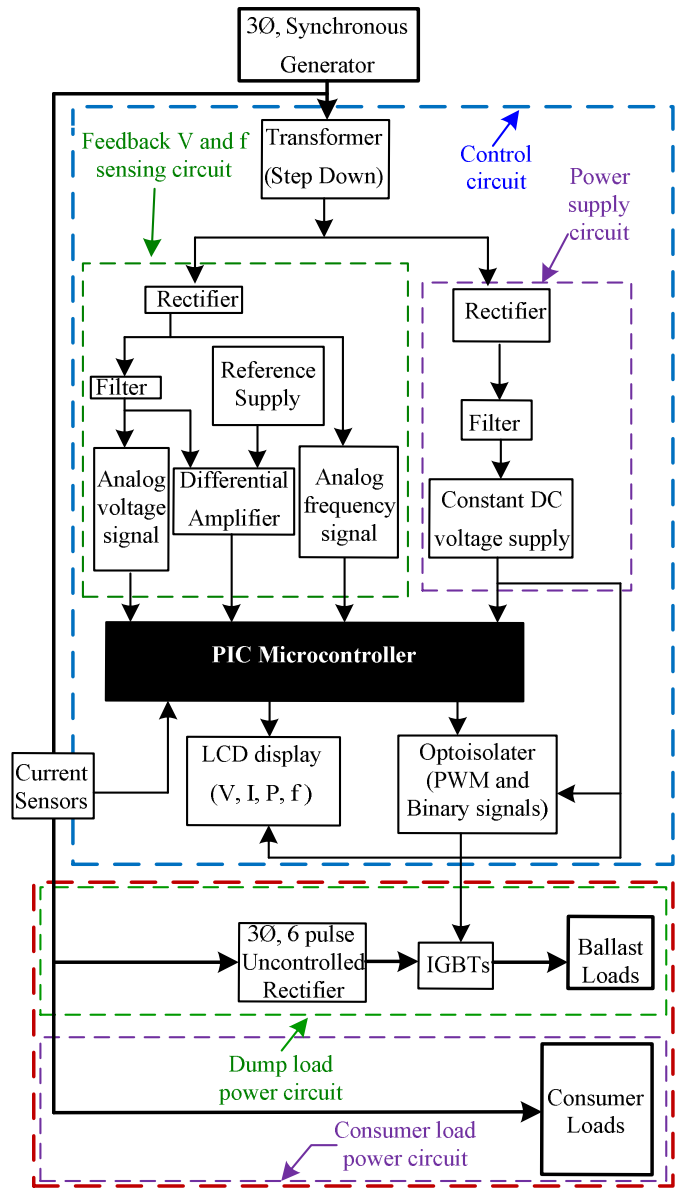

Figure 7. Block diagram of proposed ELC design.
Control circuit consists of:

- Feedback voltage and frequency sensing circuit

- Power supply circuit and

- Microcontroller, LCD display and optoisolator.

Power circuit consists of:

- Dump or ballast load power circuit and

- Consumer load power circuit.

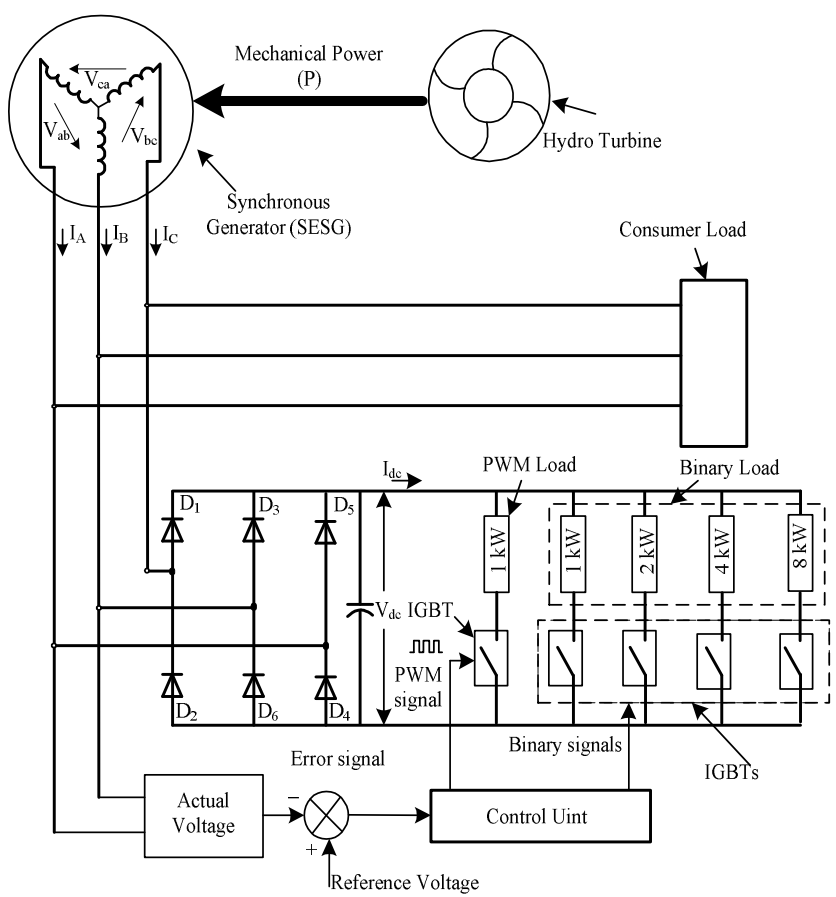

Figure 8. Power line circuit diagram of proposed ELC design.

The rating of bridge rectifier and PWM switch depends on the rated voltage and power of the synchronous generator. For $400 \mathrm{~V}$ system voltage, the DC output voltage of uncontrolled bridge rectifier is given as below:

$$
\begin{gathered}
\mathrm{V}_{\mathrm{dc}}=\left(3 \sqrt{ } 2 \mathrm{~V}_{\mathrm{L}}\right) / \pi \\
\mathrm{V}_{\mathrm{dc}}=(3 \sqrt{ } 2 \times 400) / \pi=540 \mathrm{~V}
\end{gathered}
$$

The PWM load resistance is calculated as :

$$
\mathrm{R}_{\mathrm{PWM}}=\mathrm{V}_{\mathrm{dc}}^{2} / \mathrm{P}_{\mathrm{PWM}}=540^{2} / 1000=291.6 \Omega
$$


Table II. Duty Cycle Calculation of PWM Load for 100 W Range.

\begin{tabular}{llll}
\hline $\begin{array}{l}\mathbf{P}_{\mathbf{P W M}} \\
(\mathbf{W})\end{array}$ & $\begin{array}{l}\mathbf{V}_{\mathbf{o}}=\sqrt{ } \\
\left(\mathbf{P}_{\mathbf{P W M}} \mathbf{R}_{\mathbf{P W M}}\right)(\mathbf{V})\end{array}$ & $\mathbf{I}_{\mathbf{0}}=\mathbf{V}_{\mathbf{o}} / \mathbf{R}_{\mathbf{P W M}} \mathbf{( A )}$ & $\mathbf{D}=\mathbf{V}_{\mathbf{o}} / \mathbf{V}_{\mathbf{d c}}$ \\
\hline 100 & 171 & 0.59 & 0.31 \\
200 & 241 & 0.83 & 0.45 \\
300 & 296 & 1.02 & 0.55 \\
400 & 342 & 1.17 & 0.63 \\
500 & 382 & 1.31 & 0.71 \\
600 & 418 & 1.44 & 0.77 \\
700 & 452 & 1.55 & 0.84 \\
800 & 483 & 1.65 & 0.89 \\
900 & 512 & 1.76 & 0.95 \\
1000 & 540 & 1.85 & 1 \\
\hline
\end{tabular}

Table III. Sample Load Control Sharing of Combination System.

\begin{tabular}{llllll}
\hline $\mathbf{P}_{\mathbf{C}}(\mathbf{k W})$ & $\begin{array}{l}\mathbf{P}_{\mathbf{D}}=\mathbf{P}_{\mathbf{B}}+\mathbf{P}_{\mathbf{P W M}} \\
(\mathbf{k W})\end{array}$ & $\mathbf{P}_{\mathbf{B}}(\mathbf{k W})$ & $\begin{array}{l}\text { Binary Load } \\
\text { Status }(\mathbf{8 , 4 , 2 , 1 )}\end{array}$ & $\mathbf{P}_{\mathbf{P W M}}(\mathbf{W})$ & $\mathbf{D}$ \\
\hline 15.0 & 0 & 0 & 0000 & 0 & 0 \\
12.5 & 2.50 & 2 & 0001 & 500 & 0.71 \\
11.6 & 3.40 & 3 & 0011 & 400 & 0.63 \\
9.15 & 5.85 & 5 & 0101 & 850 & 0.92 \\
8.75 & 6.25 & 6 & 0110 & 250 & 0.50 \\
7.90 & 7.10 & 7 & 0111 & 100 & 0.31 \\
4.45 & 10.55 & 10 & 1010 & 550 & 0.74 \\
2.70 & 12.30 & 12 & 1100 & 300 & 0.55 \\
0 & 15 & 15 & 1111 & 0 & 0 \\
\hline
\end{tabular}

\section{Microcontroller}

\subsection{PIC 16F887 Microcontroller}

The PIC16f887 is the one of the latest products from microchip. It features all the components which modern microcontrollers normally have. For its low price, wide range of application, high quality and easy availability. Ithas $35 \mathrm{I} / \mathrm{O}$ pin and 14 analog channels. It is an ideal solution in applications such as: the control of different process in industry, machine control devices, measurement of different values etc [9].

\subsection{Analog to Digital Converter (ADC) in PIC Microcontroller}

ADC module of PIC microcontroller have usually 5 input for 28 pin devices and 8 inputs for 40 pin devices. The conversion of analog signal to PIC ADC module results in corresponding 10 bit digital number. PIC ADC module has software selectable high and low voltage reference input to some combination of VDD, Vss, RA2 and RA3 [9].

\section{Liquid Crystal Display (LCD)}

Liquid crystal cell displays (LCDs) are used in similar applications where LEDs are used. These applications are display of numeric and alphanumeric characters in dot matrix and segmental displays.

LCDs are of two types:

1. Dynamic scattering type

2. Field effect type

\subsection{Dynamic Scattering Type}

The liquid crystal material may be one of the several components, which exhibit optical properties of a crystal though they remain in liquid form. Liquid crystal is layered between glass sheets with transparent electrodes deposited on the inside faces. When a potential is applied across the cell, charge carriers flowing through the liquid disrupt the molecular alignment and produce turbulence. When the liquid is not activated, it is transparent. When the liquid is activated the molecular turbulence causes light to be scattered in all directions and the cell appears to be bright. This phenomenon is called dynamic scattering [8].

\subsection{Field Effect Type}

The construction of a field effect liquid crystal display is similar to that of the dynamic scattering type, with the exception that two thin polarizing optical filters are placed at the inside of is also of different type from employed in the dynamic scattering cell [8].

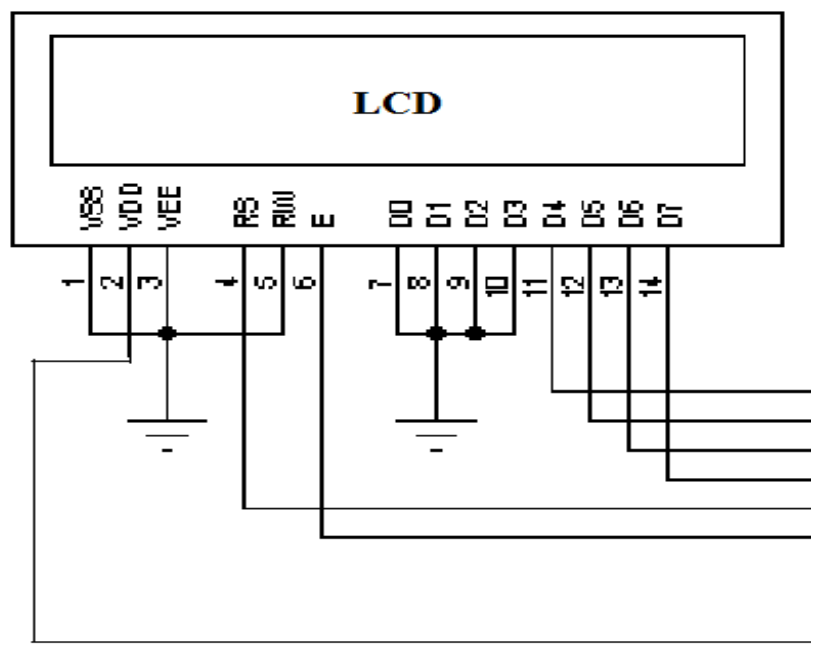

Figure 9. LCD Interfacing with microcontroller.

Table IV. Pin Definitions of Liquid Crystal Display (LCD).

\begin{tabular}{lll}
\hline No. & Symbols & Function \\
\hline 1 & VSS & To power \\
2 & VDD & power positive \\
3 & VEE & Liquid crystal display bias \\
4 & RS & Data/ command options \\
5 & R/W & Read/write choice \\
6 & E & By using the signal \\
7 & D0 & Data \\
8 & D1 & Data \\
9 & D2 & Data \\
10 & D3 & Data \\
11 & D4 & Data \\
12 & D5 & Data \\
13 & D6 & Data \\
14 & D7 & Data \\
\hline
\end{tabular}




\section{Measurement of Alternating Voltage}

\subsection{Voltage Sensor}

Voltage transformers (VTs), also referred to as "Potential Transformers" (PTs), are designed to have an accurately known transformation ratio in both magnitude and phase, $\mathrm{A}$ voltage transformer is intended to present a negligible load to the supply being measured. Voltage transformer downs the AC voltage from $440 \mathrm{~V}$ to $6 \mathrm{~V}$ according to transformer ratio. The low secondary voltage is rectified by full wave bridge rectifier to convert AC voltage to $\mathrm{DC}$ voltage. The output voltage of the rectifier contains both $\mathrm{DC}$ and $\mathrm{AC}$ (ripple) components. A filter is required to filter out ripple component to obtain the smooth DC voltage. Voltage divider circuit, variable resistor, divides the DC voltage to be an acceptable DC voltage (0- $5 \mathrm{~V})$ for microcontroller. 5.1 V zener diode is connected across at voltage divider output to protect the microcontroller from over voltage.

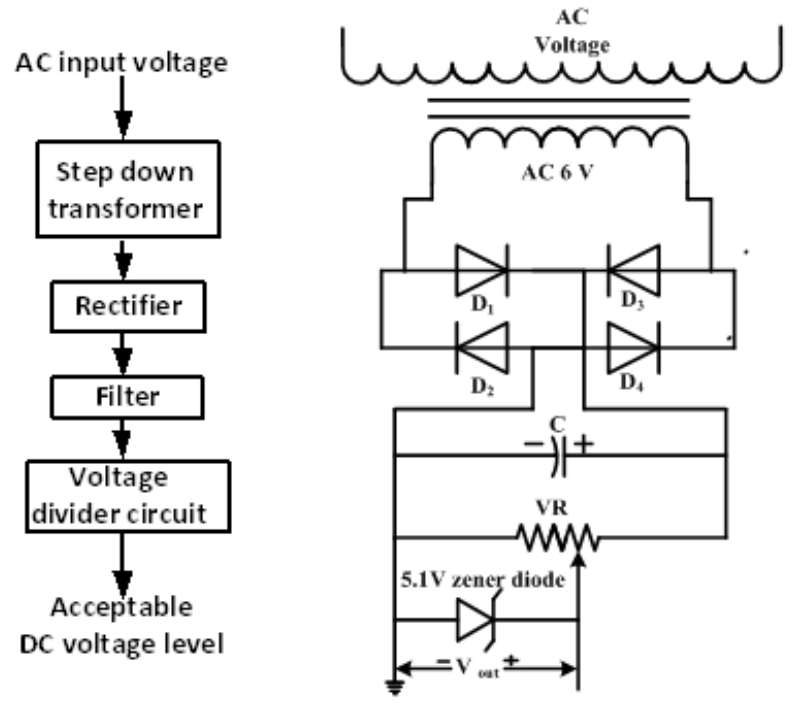

Figure 10. Voltage sensor circuit for voltage monitoring system.

\subsection{Simulation of AC Voltage Sensing and Measurement}

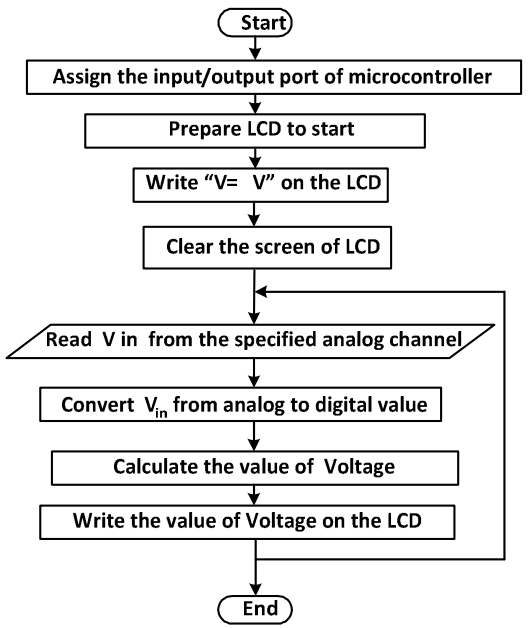

Figure 11. Flow chart program of voltage monitoring system.

The firmware program for the microcontroller is compiled with the MikroC software and simulation is done by Proteus professional software 8.0. The source code is written in MikroC software. The flow of program as shown in figure 11 goes like this: after assigning the input/output port of microcontroller, LCD is prepared to start for the system. The character "V=" and "V" are written on the LCD at the specified locations. Then the screen of LCD must be cleared to remove the previous system. Microcontroller read the input voltage from the specified analog channel and the input voltage is converted into digital value from analog value by analog-digital converter (ADC). This value has to be multiplied with voltage ratio gain and ADC gain to obtain the actual RMS value. For example, the voltage ratio gain for 500 $\mathrm{V}$ RMS voltage is $500 / 5=100$. The ADC gain for 10 bit digital number is $5 / 1023=0.004888$. After that, the value of voltage is calculated by written program and the result is monitored on the LCD by changing into the numerical character according to American Standard Code for Information Interchange (ASCII).

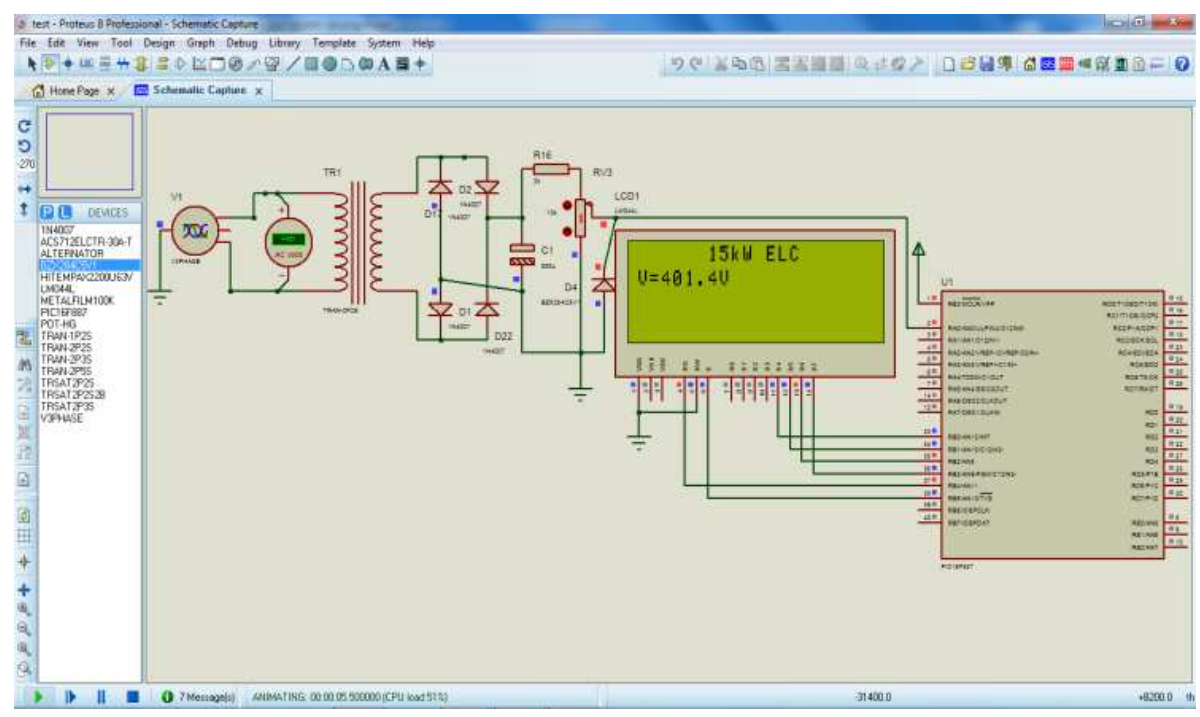

Figure 12. Simulation result of voltage monitoring system. 


\section{Measurement of Alternating Current}

\subsection{Current Sensor}

In electrical engineering, a current transformer (CT) is used for measurement of electrical currents when the current in a circuit is too high to directly apply to measuring instruments. Now, AC or DC current sensors for microcontroller based sensing are available in the market cheaply.

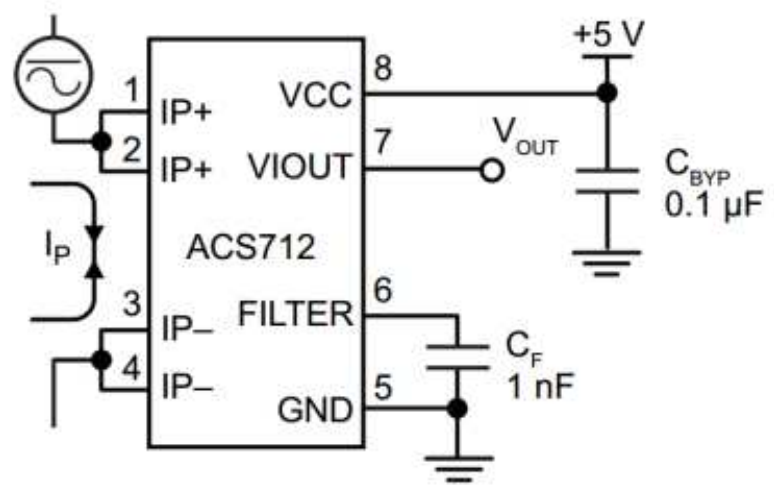

In this research, Allegro ${ }^{\mathrm{TM}} \mathrm{ACS} 712$ current sensor is used to measure the AC current. The device consists of a precise, low-offset, linear Hall circuit with a copper conduction path located near the surface of the die. Applied current flowing through this copper conduction path generates a magnetic field which the Hall IC converts into a proportional voltage. Device accuracy is optimized through the close proximity of the magnetic signal to the Hall transducer.

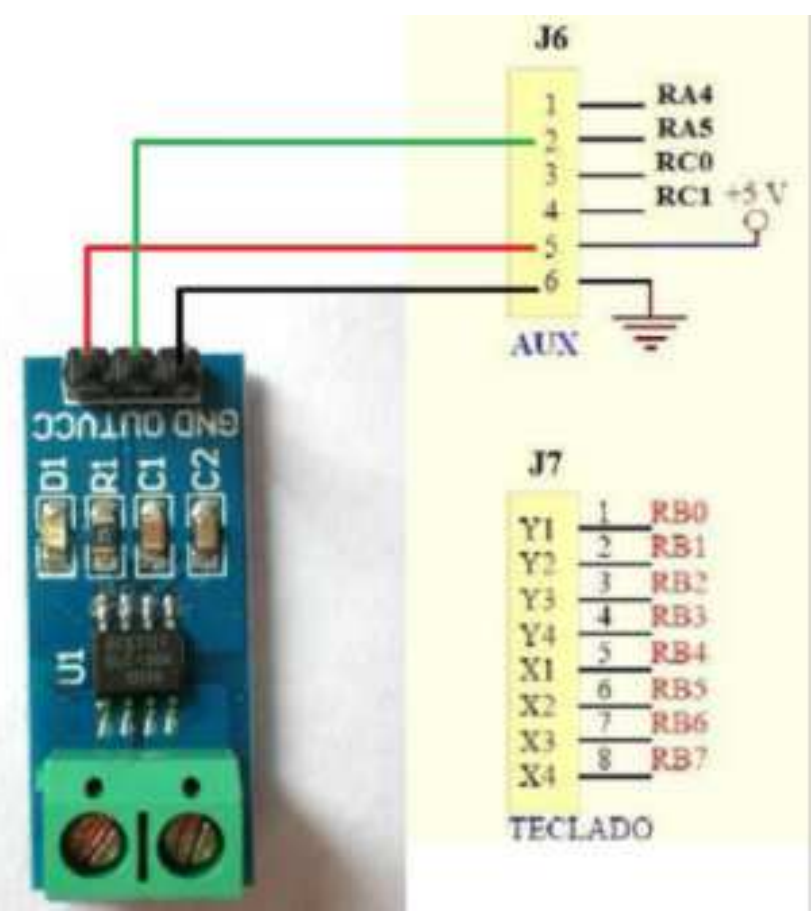

Figure 13. Typical application of ACS 712 current sensor.

The output of the device has a positive slope (>VIOUT(Q) when an increasing current flows through the primary copper conduction path (from pins 1 and 2, to pins 3 and 4), which is the path used for current sampling. The internal resistance of this conductive path is $1.2 \mathrm{~m} \Omega$ typical, providing low power loss. The thickness of the copper conductor allows survival of the device at up to $5 \times$ over current conditions. The terminals of the conductive path are electrically isolated from the signal leads (pins 5 through 8). This allows the ACS712 to be used in applications requiring electrical isolation without the use of opto-isolators or other costly isolation techniques.

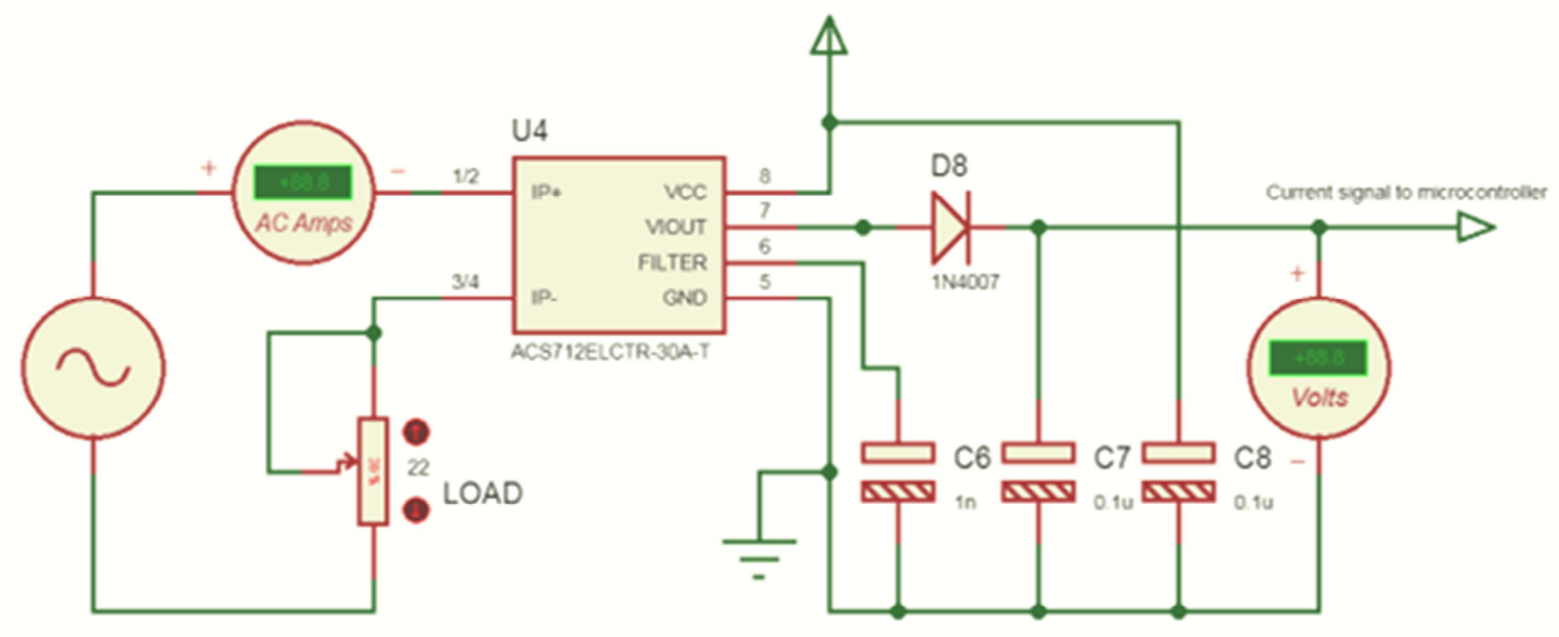

Figure 14. AC current sensing circuit diagram using ACS 712 current sensor. 
The ACS712 outputs an analog signal, VOUT, that varies linearly with the uni- or bi-directional AC or DC primary sampled current, IP, within the range specified. $\mathrm{CF}$ is recommended for noise management, with values that depend on the application [10].

\subsection{Simulation of AC Current Sensing and Measurement}

The flow of program as shown in figure 15 goes like this: after assigning the input/output port of microcontroller, LCD is prepared to start for the system. The character " $I=$ " and " $A$ " are written on the LCD at the specified locations. Then the screen of LCD must be cleared to remove the previous system. When alternating current flows through the sensor device, the output voltage of sensor also vary between $0 \mathrm{~V}$ and $5 \mathrm{~V}$ proportionally with AC current. So, to obtain the steady output voltage of sensor, a diode and a capacitor are connected to output terminal. But diode has the forward voltage drop across the anode and cathode. It reduces the output voltage of sensor. To solve that problem, various gains which refer to diode voltage drop are added to the output voltage in the program whenever load current increases or decreases one ampere. Then the value of current is calculated by written program and the result is monitored on the LCD by changing into the numerical character according to American Standard Code Information Interchange (ASCII).

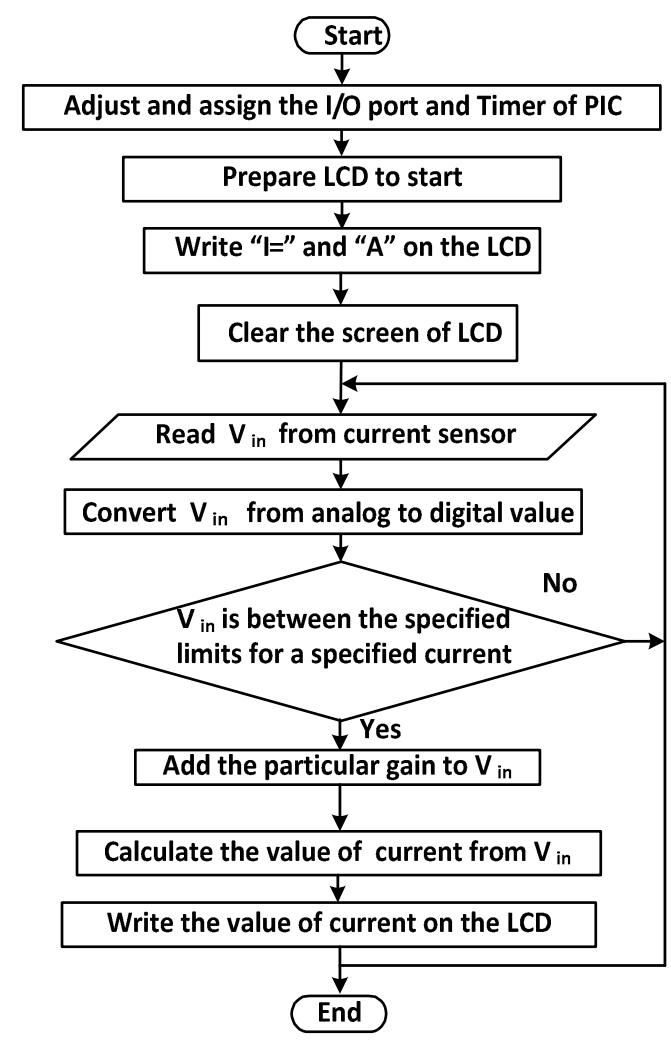

Figure 15. Flow chart program of current monitoring system

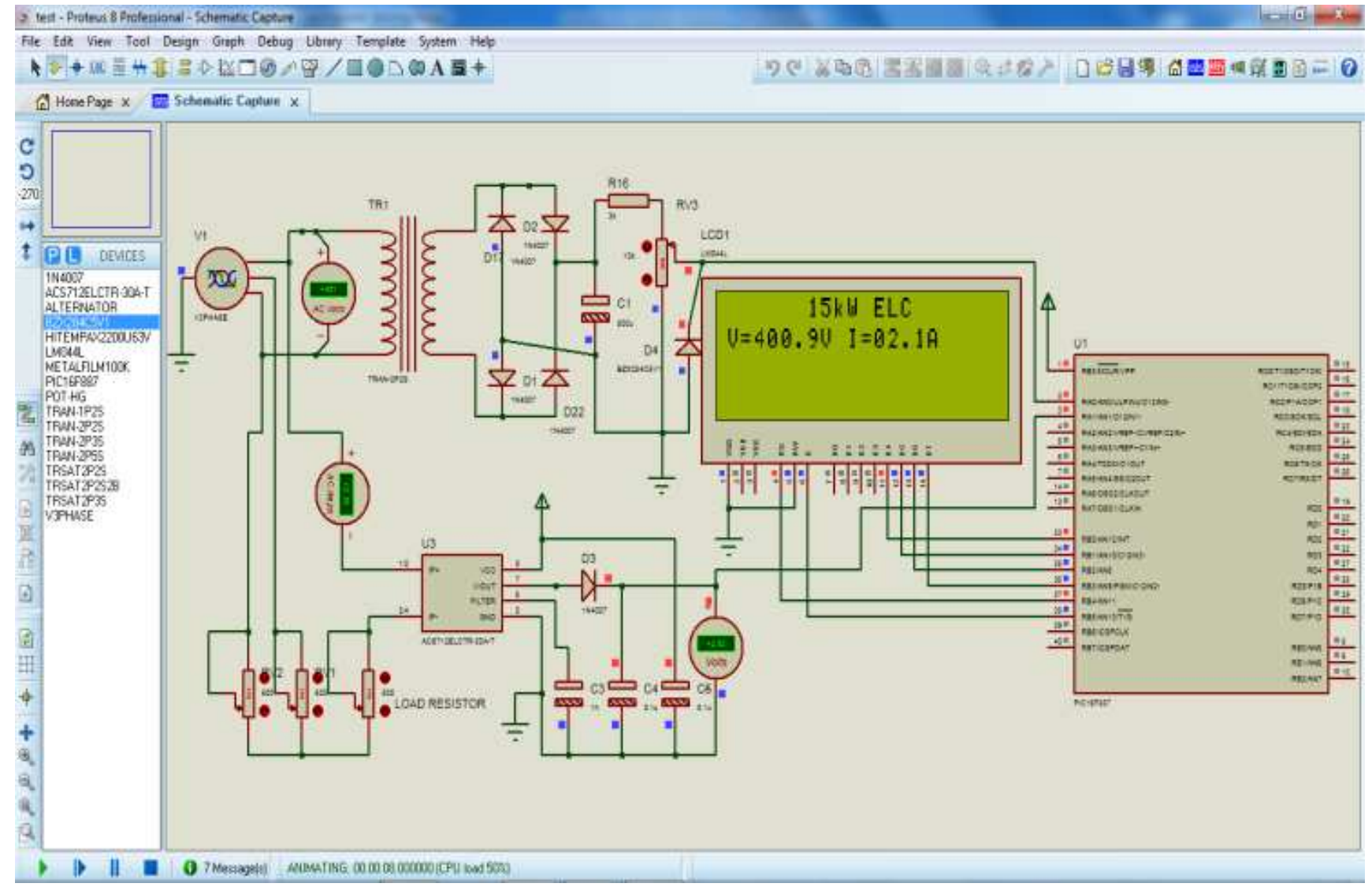

Figure 16. Simulation result of current monitoring system. 


\section{Measurement of Generated Power}

Power measurement is easily and simply done by using microcontroller and LCD after achieving the voltage and current sensing. Generated power (PG), apparent power, is measured by multiplying the voltage and current values from each sensing circuit according to the following equation.

For three phase,

$$
P G \text { or } S=\sqrt{ } 3 \mathrm{VI} \times 10^{-3} \mathrm{KVA}
$$

For single phase,

$P G$ or $S=\sqrt{ } 2$ VI $\times 10^{-3} \mathrm{KVA}$

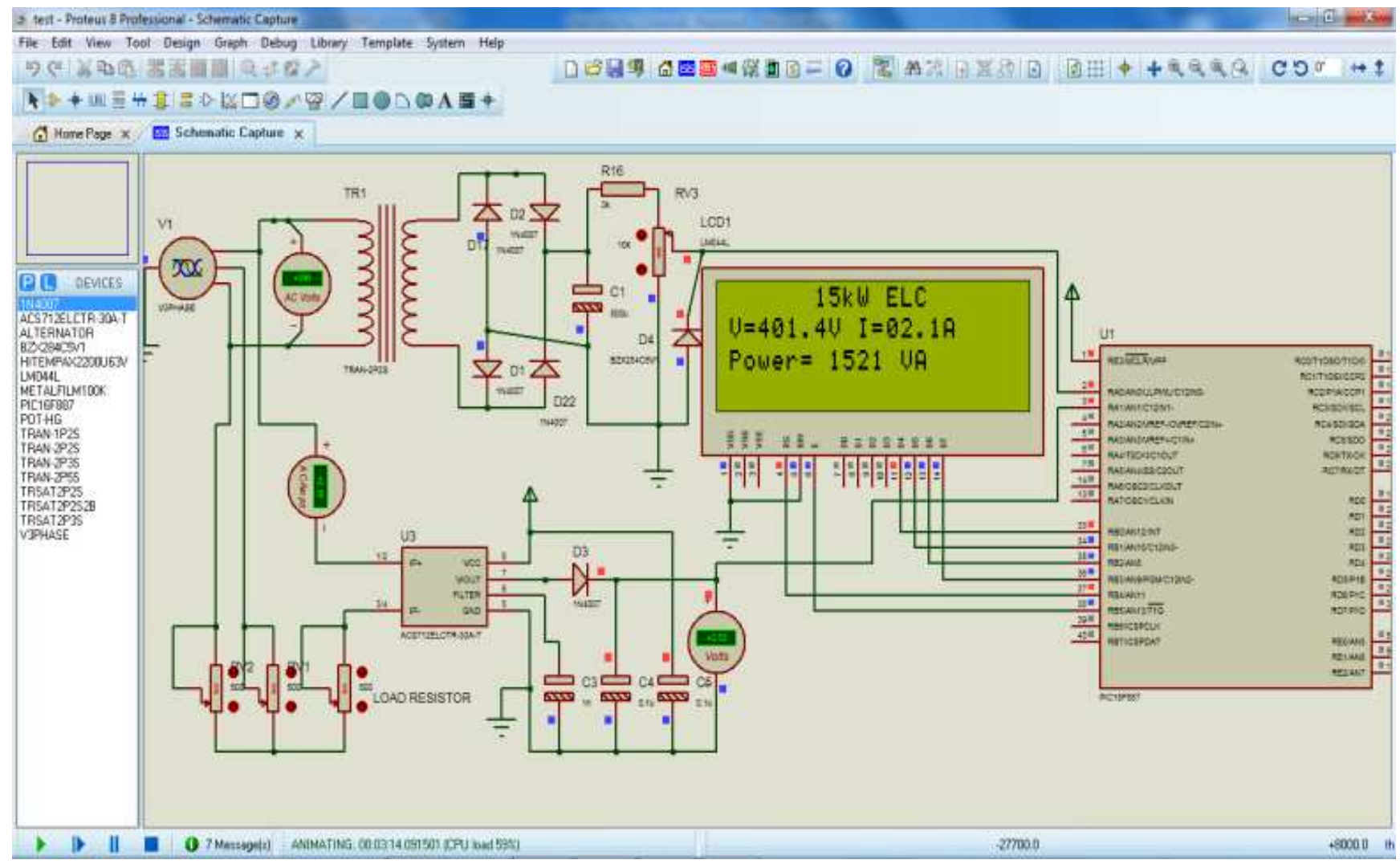

Figure 17. Simulation result of power monitoring system.

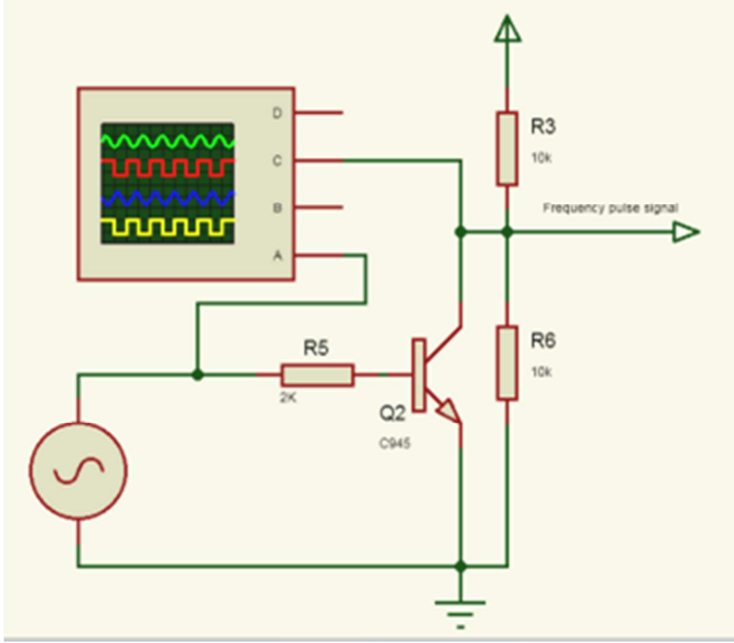

Figure 18. Frequency converter circuit diagram.

\section{Measurement of Frequency}

\subsection{Frequency Sensor}

Figure 13 shows the frequency converter circuit to convert from $\mathrm{AC}$ frequency to binary frequency signal with acceptable magnitude to be able to read by microcontroller. In circuit, series connection of resistor $R_{1}$ and $R_{2}$ operate as a voltage divider circuit. Transistor $\mathrm{Q}$ is used as a switching device. The purpose of $R_{s}$ is to limit the base current $\left(I_{B}\right)$. In the positive half cycle of the $\mathrm{AC}$ voltage, tansistor $\mathrm{Q}$ obtain the base current with forward bias and then turn on like a closed switch. Microcontroller will accept the binary signal as 0 . In the negative half cycle of AC voltage, transistor Q obtain the base current with reverse bias and then turn off like a open switch. Now, microcontroller will accept the binary signal as 1 . The binary frequency output of the circuit is shown in figure 19. 


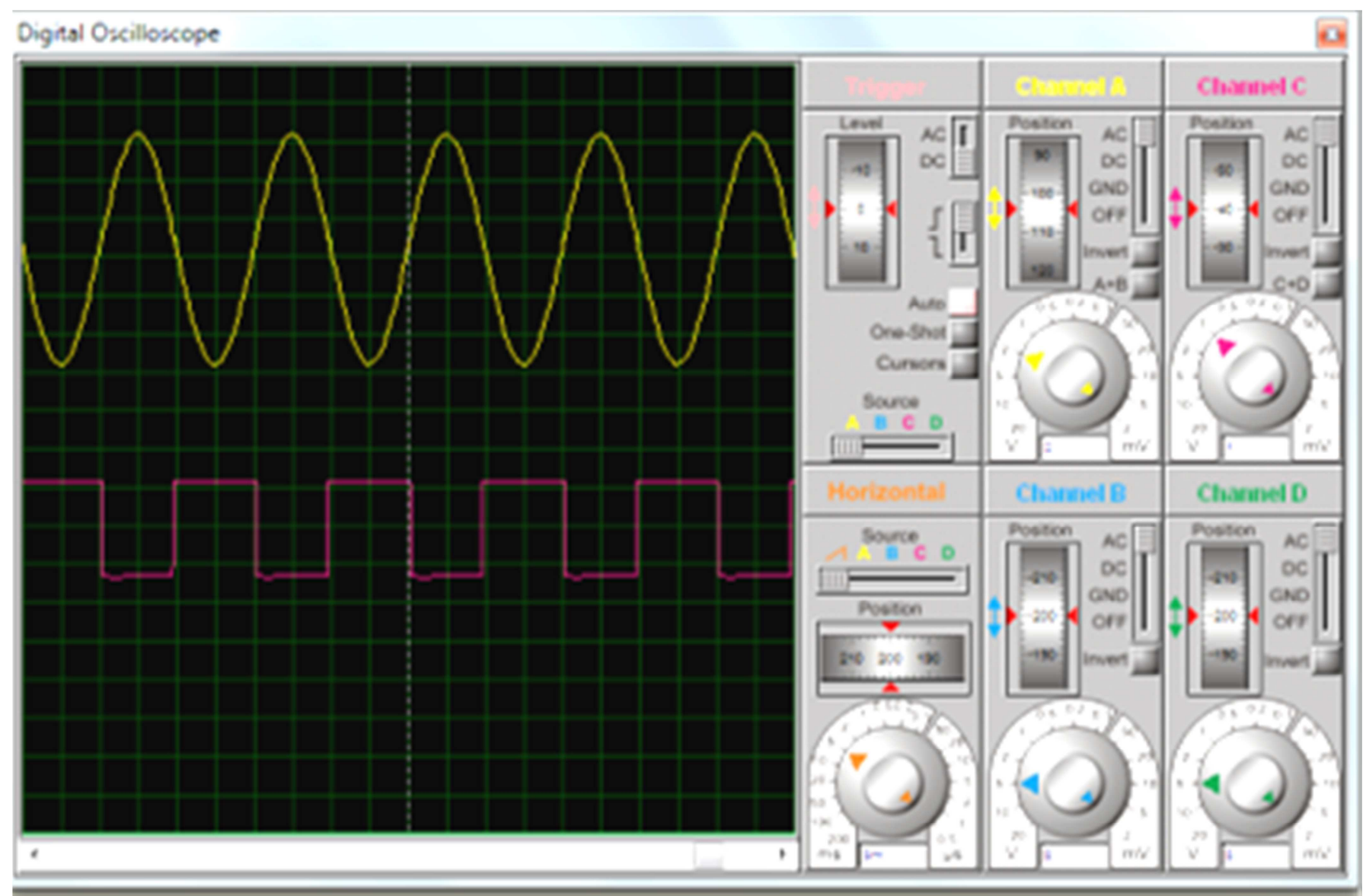

Figure 19. Binary frequency output of the frequency converter circuit.

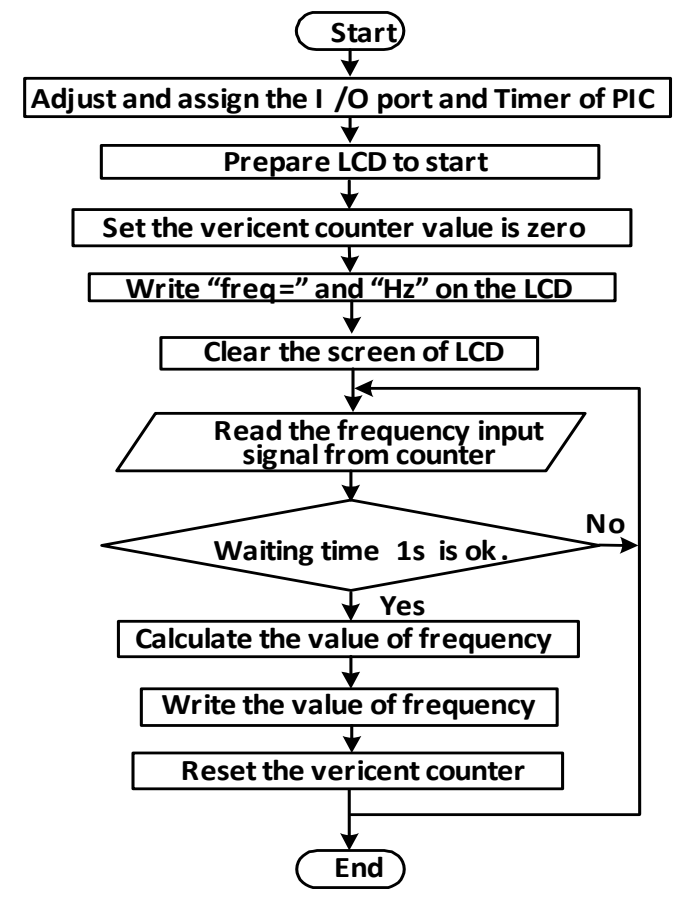

Figure 20. Flow chart program of frequency monitoring system.

\subsection{Simulation of Frequency Sensing and Measurement}

The flow of program as shown in figure 20 goes like this: after assigning the input/output port of microcontroller, LCD is prepared to start for the system. The character "freq=" and "Hz" are written on the LCD at the specified locations. Then the screen of LCD must be cleared to remove the previous system. After initialization the code enters an endless loop where it continuously performs a measurement and display operation. After an accurate 1 second delay the counter result is processed and displayed on the LCD. The main operation of this code is within the interrupt routine that both counts the input edges and obtains an accurate $1 \mathrm{~s}$ time by counting the edges of the internal oscillator clock (Fosc/8). The most important part of frequency counter is the interrupt() routine. This is where all the action and decisions are made. The interrupt code for Timer1 is very simple and all it does is increment a long variable for counting multiple input events. The more tricky interrupt code, for Timer 0 , counts time as described above. It counts 3906 overflows followed by a single 64 cycle count to reach a time of 1 second after which it captures the event count and then triggers an update to the LCD to calculate and display the frequency. 


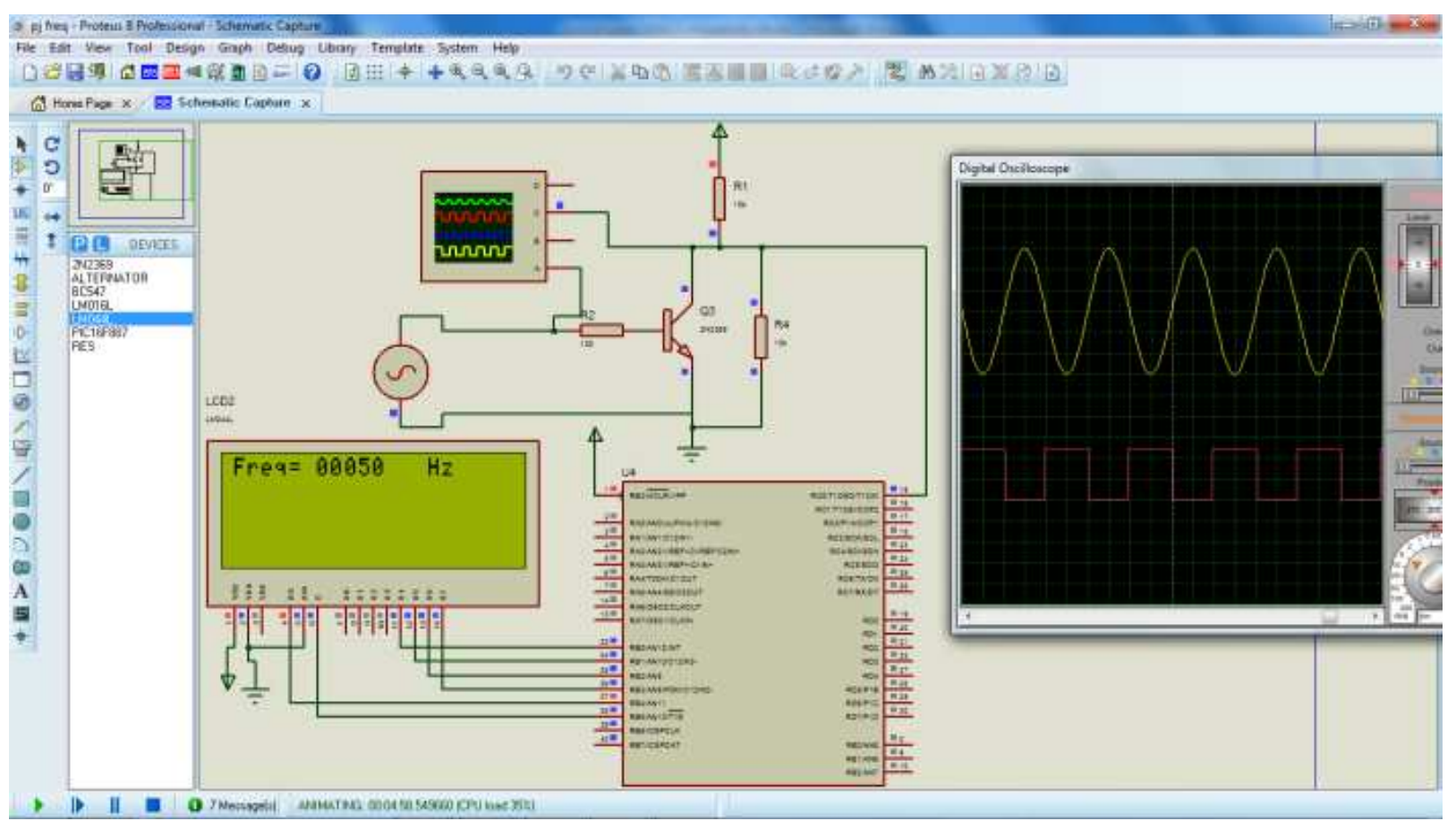

Figure 21. Simulation result of frequency monitoring system.

\section{Simulation of Proposed ELC Design}

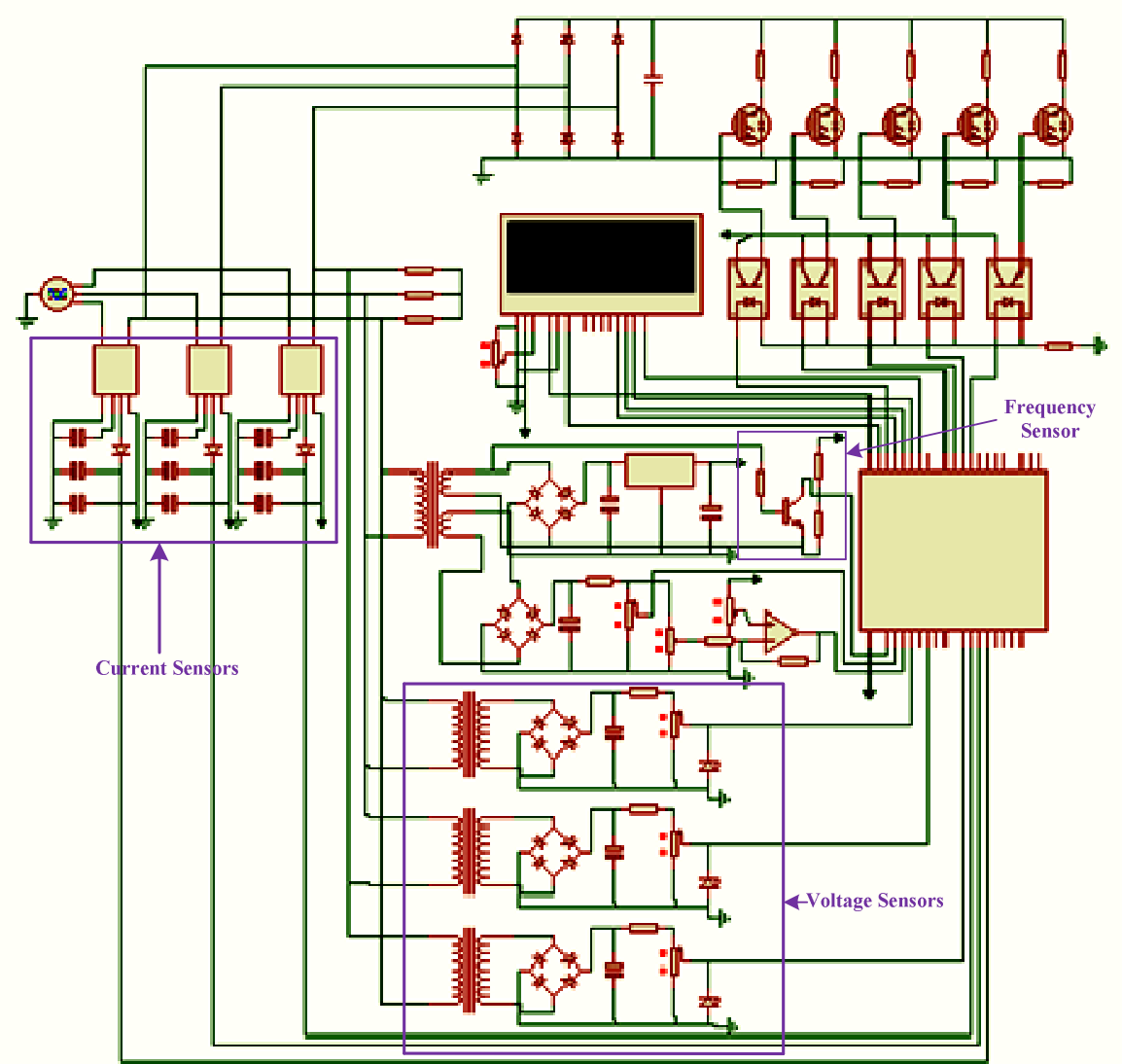

Figure 22. Complete circuit diagram of proposed ELC. 
Figure 22 shows the complete circuit diagram of proposed ELC to simulate the monitoring system. In system monitoring, three system line voltages, three line currents, generated power (PG) and system frequency are displayed on the LCD screen. In simulation, both consumer and dump load are pure resistive loads. Therefore, power factor is assumed as unity. Figure 23 shows the simulation result of monitoring system.

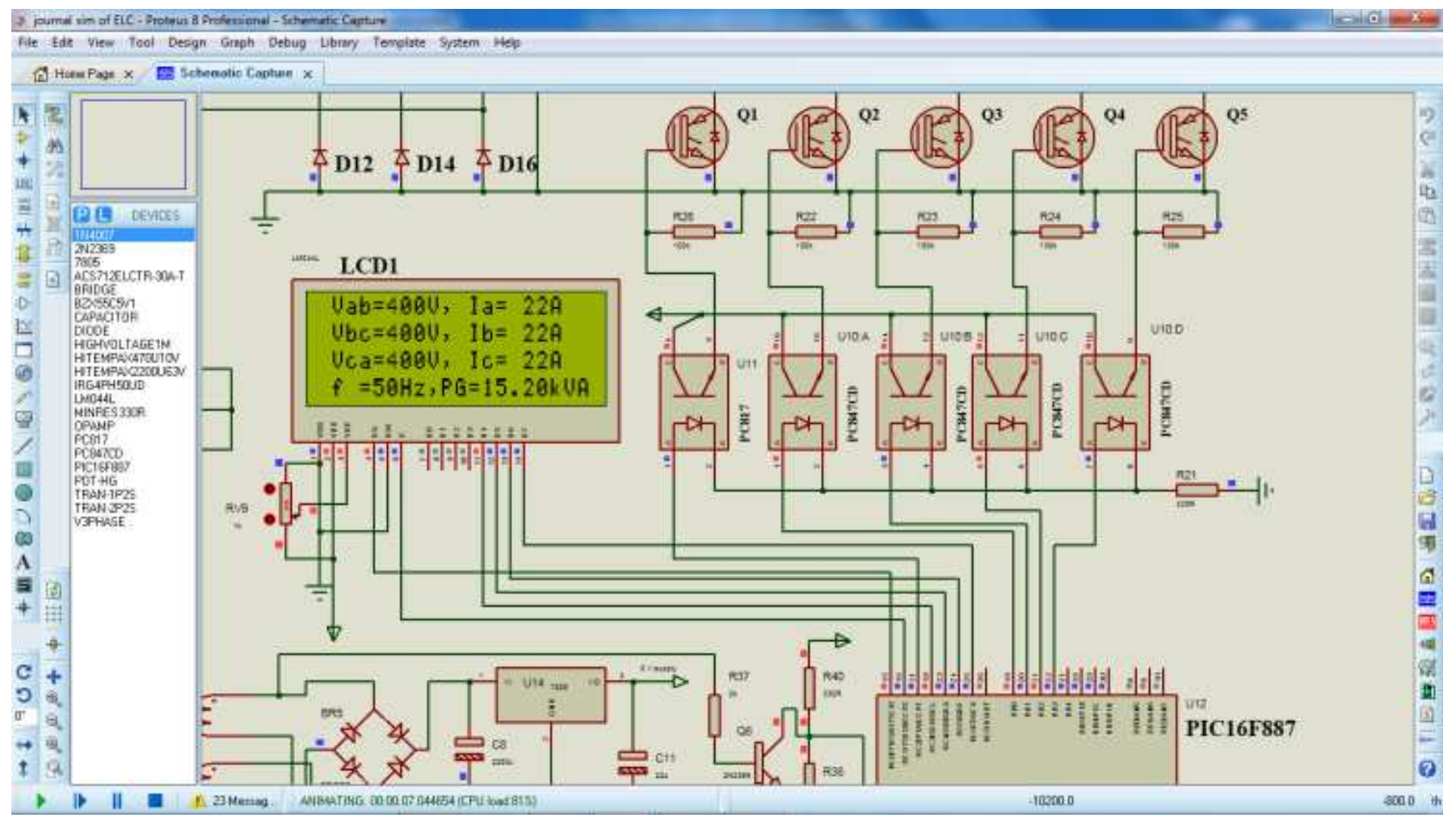

Figure 23. Overall monitoring system by simulation result.

\section{Conclusion}

The micro-hydro power generation is a viable option in remote and rural areas where grid electricity is not available. So, electronic load controllers (ELC) were being invented to be advance more and more with the wide using of micro hydropower generation. The developed microcontroller based ELC is found to be reliable, compact, cost effective and above all. Moreover, microcontroller based circuit can easily sense the system parameters such as voltage, current, frequency, power and power factor. Three system voltages, three line currents, power and system frequency must be measured and monitored on the ELC panel. In microcontroller based monitoring system, these eight parameters can be monitored on the single LCD. But, in ordinary monitoring system, eight measuring instruments have to be used for the monitoring system of ELC. The cost of these instruments is very much higher than the cost of the LCD. Using microcontroller based monitoring system not only reduces the cost of ELC but also compact the size of ELC.

\section{Acknowledgements}

The author is deeply gratitude to Dr. Myint Thein, Rector, Mandalay Technological University, for his guidance and advice. The author would like to thank to Dr. Yan Aung Oo,
Professor, Head of Department of Electrical Power Engineering, Mandalay Technological University, for his kind permission, providing encouragement and giving helpful advices and comments. The author would like to express grateful thanks to his supervisor, Dr. Aung Ze Ya, Associated Professor, Department of Electrical Power Engineering, Mandalay Technological University, for thoroughly proof-reading these paper and giving useful remarks on it. Finally, the author wishes to express his special thanks to his parents for their supports and encouragement to attain his destination without any trouble throughout his life.

\section{References}

[1] Vimal Singh Bisht, Y.R Sood, Nikhil Kushwaha, and Suryakant, Review On Electronic Load Controller,International Journal of Scientific Engineering and Technology, www.ijset.com, Volume No.1, Issue No.2 pg: 93-102, 2012

[2] Ned Mohan, Tore M. Undeland and William P. Robbins, Power Electronics, Converters, Applications, Design, 2003

[3] H.Ludens, Electronic Load Controllerfor micro-hydro system, 2010

[4] J.Portegijs, The 'Humming Bird' Electronic Load Controller/ Induction Generator Controller, 2000, 6 December 
[5] D. Henderson, An Advanced Electronic Load Controller for Control of Micro Hydroelectric Generation, IEEE TRANSACTIONS ON ENERGY CONVERSION, vol.13, pp.300-304, 1998

[6] Renerconsys, Digital load Controller for Synchronous Generator: Manual Instruction, 2010

[7] J. M. Jacob, Power Electronics: Principles and Applications, Vikas Publishing House, 2002.

\section{Biography}

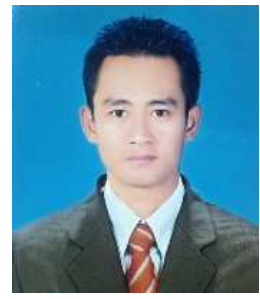

\section{Mr. Nan Win Aung}

He received the BE degree in Electrical Power Engineering from Technological University (Kyaukse), Myanmar in 2005. Since December 2006, he became a Demonstrator at Technological University (Sittwe) under Ministry of Science and Technology, Myanmar. And then, he obtained ME degree in Electrical Power Engineering from Mandalay Technological University, Myanmar, in 2011 by serving his duty. Now, his mother unit is Technological University (Myitkyinar) and he is attending Ph.D degree in Electrical Power Engineering at Mandalay Technological University, Mandalay, Myanmar.
[8] Dogan Ibrahim, Advanced PIC Microcontroller projects in C, 2008

[9] Datasheet and Guide Book ofJ204ALiquid CrystalDisplay(LCD), www.alldatasheet.com/J204A

[10] DatasheetandGuideBook ofPIC 16F887Microcontroller, www.alldatasheet.com/PIC

[11] DatasheetandGuideBookofACS www.alldatasheet.com/Acs712.

712

ACcurrentsensor,

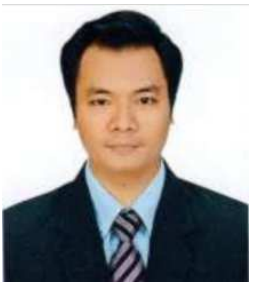

Dr, Aung Ze Ya

Dr. Aung Ze Ya was born in Yangon in 1976. He awarded B.E (EP) in 2000 and M.E (EP) in 2002 fromMandalay Technological University and Ph.D (EP) from Yangon Technological University in 2004. He also gained the Master Trainer of Renewable Energy Systems from NEDO (Japan) in 2011. He collaborated with Earth Institute of Columbia University and HOMER Energy (USA) throughout the World Bank Mission of Development of Myanmar National Electrification Plan towards Universal Access in 2014. Currently, he is working as an Associate Professor at Mandalay Technological University. His research interests are Sustainable Development, Renewable Energy Systems, PV Hybrid Micro Grid, Smart Grid, Smart Home System, Electrical Designs, Power Electronics and Drives. 